\title{
Decision Support System in Corporate Intelligence
}

\author{
Monika Varshney ${ }^{1}$, Dr. Azad Kumar Srivastava ${ }^{2}$ \\ Research Scholar, Department of Computer Science, Mewar University, Gangar, Chittorgarh (Raj) India ${ }^{1}$ \\ Supervisor, Department of Computer Science, Mewar University, Gangar, Chittorgarh (Raj) India ${ }^{2}$
}

\begin{abstract}
A Decision Support System (DSS) is a computer-based information system that supports business or corporate organizational decision-making activities. DSSs serve the management, operations, and planning levels of an organization (usually mid and higher management) and help to make decisions. Corporate intelligence represents the tools and systems that play a key role in the strategic planning process within a corporation. These Business Intelligence systems allow a company to gather, store, access and analyze corporate data to aid in decision-making. Generally these systems will illustrate business intelligence in the areas of customer profiling, customer support, market research, market segmentation, product profitability, statistical analysis, and inventory and distribution analysis just to name a few. This paper presents a relationship between decision support system and corporate intelligence to find out the true picture of business parameters, to plan strategies for the future and direct business resources towards achieving growth potential.
\end{abstract}

Keywords: Decision Support System; Corporate Intelligence; Decision Making; Information System; Data Analysis.

\section{INTRODUCTION}

Decision Supports Systems (DSS) are computer-based information systems designed in such a way that help managers to select one of the many alternative solutions to a problem. The general term 'computer-based information systems' is a constellation of a variety of information systems such as office automation systems, transaction processing systems, management information systems and management support systems. It is possible to automate some of the decision making processes in a large, computer-based DSS which is sophisticated and analyze huge amount of information fast. It helps corporate to increase market share, reduce costs, increase profitability and enhance quality. The nature of problem itself plays the main role in a process of decision making. A DSS is an interactive computer base information system with an organized collection of models, people, procedures, software, databases, telecommunication, and devices, which helps decision makers to solve unstructured or semi-structured business problems.

\section{DECISION SUPPORT SYSTEM}

The concept of decision support has evolved from two main areas of research: The theoretical studies of organizational decision making done at the Carnegie Institute of Technology during the late 1950s and early 1960s, and the technical work on Technology in the 1960s. DSS became an area of research of its own in the middle of the 1970s, before gaining in intensity during the 1980s. In the middle and late 1980s, executive information systems (EIS), group decision support systems (GDSS), and organizational decision support systems (ODSS) evolved from the single user and model-oriented DSS. Computerized decision support systems became practical with the development of minicomputers, timeshare operating systems and distributed computing.

The definition and scope of DSS has been migrating over the years. In the 1970s DSS was described as "a computerbased system to aid decision making". In the late 1970s the DSS movement started focusing on "interactive computerbased systems which help decision-makers utilize data bases and models to solve ill-structured problems". In the 1980s DSS should provide systems "using suitable and available technology to improve effectiveness of managerial and professional activities", and towards the end of 1980s DSS faced a new challenge towards the design of intelligent workstations.

Using the relationship with the user as the criterion, Haettenschwiler differentiates passive, active, and cooperative DSS. A passive DSS is a system that aids the process of decision making, but that cannot bring out explicit decision suggestions or solutions. An active DSS can bring out such decision suggestions or solutions. A cooperative DSS allows the decision maker (or its advisor) to modify, complete, or refine the decision suggestions provided by the system, before sending them back to the system for validation. The system again improves, completes, and refines the suggestions of the decision maker and sends them back to them for validation. The whole process then starts again, until a consolidated solution is generated. 
Taxonomy for DSS has been created by Daniel Power. Using the mode of assistance as the criterion, Power differentiates communication-driven DSS, data-driven DSS, document-driven DSS, knowledge-driven DSS, and model-driven DSS.

\section{A. Data driven DSS}

Includes file drawer and management reporting systems, data warehousing and analysis systems, Executive Information Systems (EIS) and Geographic Information Systems (GIS). Data-Driven DSS emphasize access to and manipulation of large databases of structured data and especially a time-series of internal company data and sometimes external data.

\section{B. Model driven DSS}

Includes systems that use accounting and financial models, representational models, and optimization models. ModelDriven DSS emphasize access to and manipulation of a model. Simple statistical and analytical tools provide the most elementary level of functionality. Some OLAP systems that allow complex analysis of data may be classified as hybrid DSS systems providing modeling, data retrieval and data summarization functionality. Model-Driven DSS use data and parameters provided by decision-makers to aid them in analyzing a situation, but they are not usually data intensive.

\section{Knowledge driven DSS}

We can suggest or recommend actions to managers. These DSS are person-computer systems with specialized problem-solving expertise. The "expertise" consists of knowledge about a particular domain, understanding of problems within that domain, and "skill" at solving some of these problems. A related concept is Data Mining. It refers to a class of analytical applications that search for hidden patterns in a database. Data mining is the process of sifting through large amounts of data to produce data content relationships. Data Mining tools can be used to create hybrid Data-Driven and Knowledge-Driven DSS.

\section{Document driven DSS}

Integrates a variety of storage and processing technologies to provide complete document retrieval and analysis. The Web provides access to large document databases including databases of hypertext documents, images, sounds and video. A search engine is a powerful decision-aiding tool associated with this type of DSS.

\section{E. Communication driven and group DSS}

Where communication driven DSS includes communication, collaboration and coordination and GDSS focus on supporting groups of decision makers to analyze problem situations and performing group decision making tasks.

\section{CORPORATE INTELLIGENCE}

It provides vital information on current and future business partners and other matters when organizations want to reduce risk, enter new markets, solve corporate problems, undertake corporate investigations and enhance business opportunities. Companies often seek corporate intelligence prior to entering into investments, joint ventures and acquisitions. It can be crucial in doing business in emerging offshore markets where reliable information on individuals and organizations can be scarce. It complements and augments the financial and legal due diligence undertaken by mainstream advisers.

Extracting Corporate Intelligence includes: 'integrity analysis' of important persons \& of the corporate concern involved, forensic accounting \& 'doing investigations' of concerned data, facts, projects, business risks involved and key persons for an intelligent decision making and any likely future or imminent 'litigation'. The global network of corporate intelligence practitioners locate, collect and analyze information from public and confidential sources around the world.

Corporate intelligence also identifies and mitigates potential or current risks facing an organization and help resolve questions arising from quantitative abnormalities. Corporate intelligence is the focused collection and analysis of information regarding an unfamiliar subject that is used to deliver key insights to decision makers in support of a major business concern, corporate action such as an investment or acquisition, internal inquiry or consideration of risk factors. Corporate intelligence practitioners will find the combination of the distinct qualitative and quantitative skill sets to be the most needed sills to identify and mitigate risks, interrogate the facts of an alleged circumstance or rectify the aftermath of a negative event.

The practice of corporate intelligence centers on research and analysis of qualitative information regarding a subject of interest, being either an entity, a person, or an issue. Corporate intelligence is the process of reviewing key aspects of a company to determine its strengths and weaknesses. Investors and industry analysts review corporations to determine if 
they provide solid growth opportunities to outside investors. This paper presents decision support system integration with corporate analysis to identify business opportunities, strategize for the future and direct business resources towards that growth potential.

\section{DSS - CORPORATE INTELLIGENCE RELATIONSHIP}

The key similarity in these two definitions is "making corporate decisions", and in particular both concepts are focused on helping to make these decisions in a better and easier way. The other important similarity is they both involve decision making "based on data". After analyzing both corporate intelligence and DSS, Corporate Intelligence is a broad category of applications and technologies for gathering, storing, analyzing, and providing access to data to help enterprise users make better business decisions. In the same manner A decision support system (DSS) is a computer program application that analyzes business data and presents it so that users can make business decisions more easily.

The key similarity in these two definitions is "making business decisions", and in particular both concepts are focused on helping to make these decisions in a better and easier way. The other important similarity is they both involve decision making "based on data".

In the early 1970's Scott-Morton defined DSS as "interactive computer based systems, which help decision makers utilize data and models to solve unstructured problems.

Keen and Scott -Morton (1978) provided another classic definition: "Decision support systems couple the intellectual resources of individuals with the capabilities of the computer to improve the quality of decisions. It is a computer a computer--based support system for management decision makers who deal with semi- structured problems"

To make it much clearer we introduce pictorial summary of corporate intelligence and DSS components on this Figure.

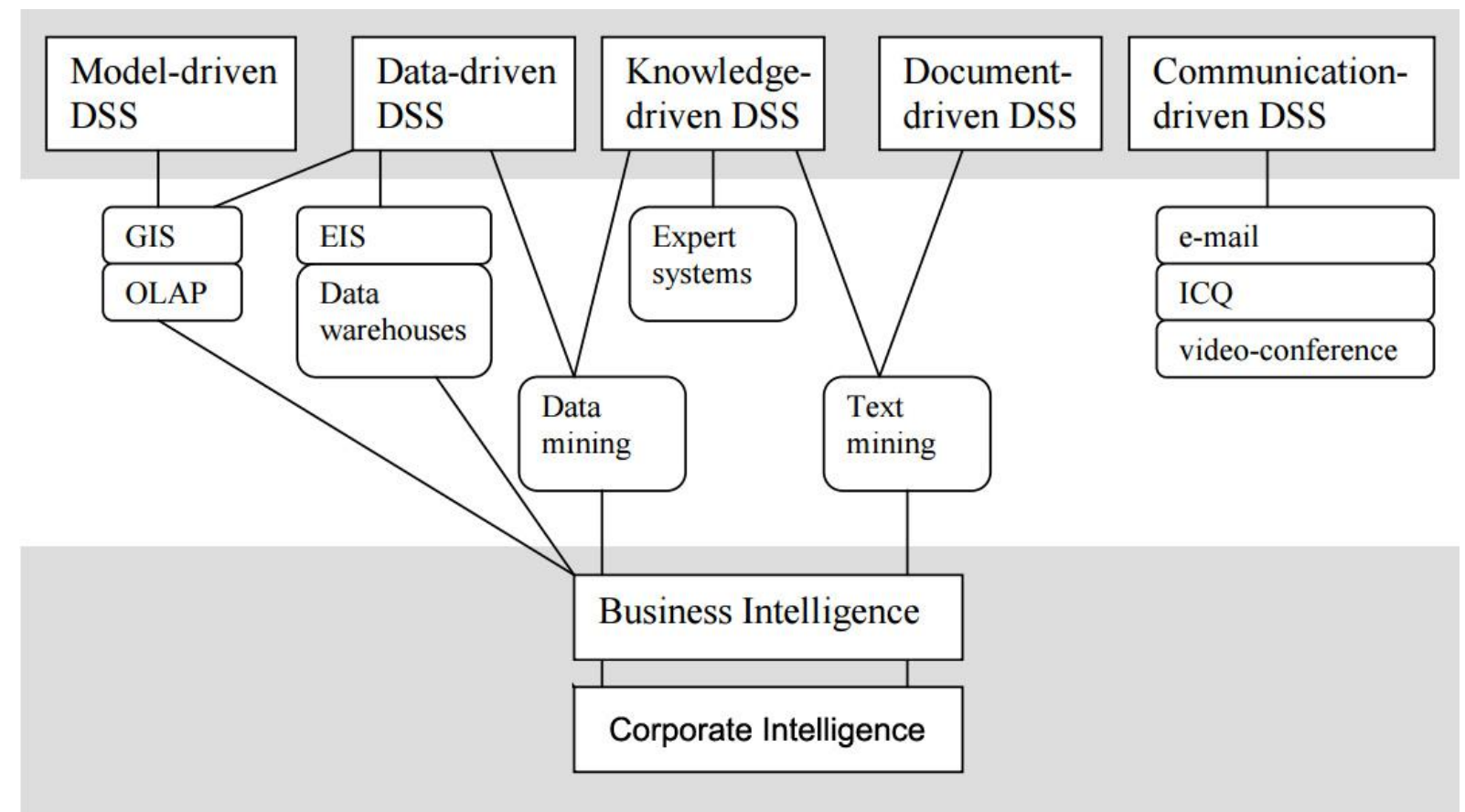

Figure: Components of BI and DSS

\section{CONCLUSION}

Corporate intelligence is a set of methodologies, processes, architecture, and technologies that transforms raw data into meaningful and useful information used to enable more effective strategic, tactical and operational insight and decision making. As well as Decision Support Systems (DSS) are a specific class of computerized information system that supports business and organizational decision-making activities. A properly-designed DSS is an interactive softwarebased system intended to help decision makers compile useful information from raw data, documents, personal knowledge, and/or business models to identify and solve problems and make decisions. So Decision support system is highly related with corporate intelligence. 


\section{IJARCCE}

\section{ACKNOWLEDGEMENT}

Monika Varshney is very grateful to the Prof. (Dr.) S. Dixit, advisor to chancellor, Mewar University, Chittorgarh (Raj.) and Mr. Pradeep Kumar Sharma, Assistant Professor, Department of Computer Science, Vivekananda College of Technology and Management, Mathura Bypass near Khair Road, Aligarh (UP) for fruitful discussion and proper guidance.

\section{REFERENCES}

[1] D.J. Power, Decision support systems: concepts and resources for managers, Westport, Conn., Quorum Books, 2002

[2] http://www.wisegeek.com/what-is-corporate-analysis.html

[3] http://www.ehow.com/about_5286081_corporate-analysis.html

[4] http://innovateonpurpose.blogspot.in/2008/09/difference-between-corporate-and.html

[5] http://en.wikipedia.org/wiki/Corporation

[6] http://www.wisegeek.com/what-is-corporate-analysis.html

[7] http://timoelliott.com/blog/2011/03/business-analytics-vs-business-intelligence.html

[8] http://peterjamesthomas.com/2009/03/28/business-analytics-vs-business-intelligence/

[9] http://www.networkworld.com/article/2266108/applications/analytics-versus-intelligence.html

[10] http://www.wisegeek.com/what-is-corporate-analysis.html

[11] http://www.igi-global.com/journal/international-journal-business-intelligence-research/1168

[12] Andreas Felsberger, etal; a review of decision support systems for manufacturing system, SamI40 workshop at i-KNOW '16 October 18-19, 2016, Graz, Austria

[13] Wu, J. Business Intelligence: What is Business Intelligence? DM Review.com, 2000. [Online] URL: http://www.dmreview.com/article sub.cfm?articleId=1924

[14] K P Tripathi / Indian Journal of Computer Science and Engineering (IJCSE) 